\title{
Portraying the relativist spectrum
}

\section{Martin Kusch: Relativism in the philosophy of science, Cambridge: Cambridge University Press, 2020, 69 pp, $£ 15$}

\section{Markus Seidel $^{1}$}

Accepted: 19 May 2021 / Published online: 8 June 2021

(c) The Author(s) 2021

This very short book, around 70 pages, is written by an outstanding expert on and sympathizer of relativism, Martin Kusch. As is to be expected from such a short book, it does not provide a comprehensive overview of relativism in the philosophy of science. Indeed, I am sceptical in general whether the format of the Elementsseries by CUP is a sensible format for philosophical discussion at all. The advertisement on the website claims that "this series of Elements in Philosophy of Science provides an extensive overview of the themes, topics, and debates which constitute the philosophy of science. Distinguished specialists provide an up-to-date summary of the results of current research on their topics, as well as offering their own take on those topics and drawing original conclusions." That is an attempt at squaring the circle: It is impossible to give both an extensive overview of the debates covered by the series and to draw original conclusions in just 70 pages. Hence if this volume does not succeed in fulfilling these aims, it is most certainly not Kusch's fault. Given the restrictions and aim of the series-format, Kusch is doing a marvelous job. The book is written clearly, it is comprehensible for non-experts and, on top of that, Kusch provides interesting perspectives for experts, especially in his chapters on van Fraassen and the sociology of scientific knowledge (SSK). It would be unfair to bemoan what is missing from the book in a review that focusses on the book rather than the series. So, in sum, I recommend the book because Kusch's ability and knowledge of the debates around relativism in the philosophy of science compensate for the ill-conceived format of the series.

After a short introduction outlining the scope of the book, Kusch asks "What is Relativism?" in Chapter 2. In addition to presenting the scope of relativistic positions, Kusch also sketches motivations for relativism and summarizes Paul Boghossian's pro and con arguments. Kusch restricts his discussion of relativism in philosophy of science to epistemic relativism, i.e., relativism with respect to knowledge or justification: “Throughout this Element, 'relativism' and 'absolutism' refer to

Markus Seidel

markus.seidel@wwu.de

1 Center for Philosophy of Science, University of Münster, Münster, Germany 
epistemic relativism and epistemic absolutism, respectively" (2). I take it that this restriction is mainly due to the spatial restrictions of the book, since relativism in philosophy of science surely cannot be thought of merely as the epistemic variant: strains of e.g., ontological, alethic, and semantic relativism are also easily found in the work of the authors Kusch discusses. Kusch himself even explicitly notes this with respect to the semantic relativism of SSK (cf. 46). To my mind, it is nevertheless wise for him to restrict himself to the epistemic variant.

However, I have one minor concern here. Kusch distinguishes between alethic relativism, relativism with respect to truth(s), and epistemic relativism (see 2). On the same page, he then restricts the scope of the book to the latter. This is fine, but the reader is surprised that Kusch does not seem to stick very closely to his own restriction for his argument. For example, in the abstract of the book, we read that Kusch "argues that defensible forms of relativism all deny that any sense can be made of a scientific result being absolutely true or justified" [my italics]. How can Kusch argue for this claim if alethic relativism is not within the scope of the book? Similar remarks can be made about other parts of the book (e.g., 6-7). This suggests either Kusch is oblivious of his own restriction, or he thinks that the epistemic and the alethic variant should not, or cannot, be distinguished very strictly. If the latter, to my mind, it would have been helpful to inform the reader of this instead of claiming that "relativism" only refers to epistemic relativism throughout the book.

Kusch does not define epistemic relativism by providing a list of necessary and sufficient conditions. Rather, he characterizes the "relativist spectrum" as comprising several ideas: Dependence on epistemic standards, Plurality of standards, Conflict of epistemic verdicts (in two possible variants), Conversion between sets of standards, and Symmetry of standards (in four possible variants) (see 2-4). I appreciate this move since it allows Kusch to count positions of different strengths as relativistic, as they all fall somewhere on the spectrum without necessarily subscribing to all the same or even all these theses.

However, conceiving of relativism in terms of a spectrum, we run the risk that everybody somehow falls on the relativist side. Take myself: I have published a book-length criticism of epistemic relativism (cf. Seidel 2014), but-I guess-I would subscribe to all ideas cited by Kusch, with the possible exception of symmetry. Am I a relativist or not? Since Kusch himself sees the theses comprised by symmetry as "in many ways, the heart of relativism" (4), it might be that I very well still do not count as a relativist on Kusch's spectrum. Perhaps, despite Kusch's insistence on not treating the ideas in the spectrum as necessary and sufficient conditions, symmetry is necessary for relativism. (Note that 'heart of relativism' is too metaphorical an expression to be sure here). Also, in Kusch (2016), he names more features of epistemic relativism and distinguishes between essential and non-essential features. I am not sure how this relates to this characterization. In any case, characterizing relativism via a spectrum of ideas has advantages and disadvantages: It covers many different positions falling on the relativist spectrum, but it risks getting everybody, even absolutists, aboard the relativism ship. That cannot be right.

In Chapter 3, Kusch does a great job at describing relativist elements in Kuhn, Feyerabend, scientific pluralism and scientific perspectivism-albeit, due to the format, in broad brushstrokes. Before ending the book with some notes on the 
relation between relativism and post-truth, Chapters 4 and 5 present the main argument of the book. In Chapter 4, Kusch provides a relativist interpretation of Bas van Fraassen's constructive empiricism, and in Chapter 5, he presents a charitable interpretation of SSK. Both chapters supply illuminating perspectives on relativism in philosophy of science. Kusch's relativist interpretation of van Fraassen's (meta-) philosophical view on stances promises to equip the relativist with strong arguments from a new perspective. Let me focus, however, a bit more on Chapter 5, since I know the relativism of SSK better.

Kusch defends the Strong Program or SSK, associated with David Bloor and Barry Barnes, against criticism by Paul Boghossian and Michael Friedman. I do not have the space to comment extensively on Kusch's well-considered arguments. Instead, I will make just one remark, from which results one problem and one compliment for Kusch. What I want to remark is that SSK very often is simply unclear about the strengths of its theses. This results in one problem for Kusch. Kusch does not think that SSK is committed to the thesis of EQUAL VALIDITY (cf. 51), which is the thesis that different sets of standards are equally true or valid (cf. 3f.). Granted, many of SSK's statements directly oppose EQUAL VALIDITY. But then you also find quotes by Bloor where, by implication, he seems to admit that science and myth are both true (cf. Bloor 2008, 13; see for exposition Seidel 2014, 17). So, I fear, I do not have Kusch's confidence about SSK's pretensions.

My remark about SSK's unclarity, however, also results in praise for Kusch, as he clarifies the position of the Strong Program in an illuminating fashion. The problem with the Strong Programers' relativism always was what Andre Kukla has called 'reverse switcheroos': They seem to be making a relativist claim and then step back to an innocuous form of methodological relativism once the relativist claim is attacked (cf. Kukla 2000, x). Kusch's presentation of the Strong Program forestalls this move. The reason is that Kusch distinguishes clearly between SSK's methodological relativism - the idea of bracketing off evaluation for the purposes of conducting a causal explanation (cf. Bloor 2004, 937, see also Bloor 1991, 158) —and the "philosophical-substantive" (62) relativist claims of LOCALITY, the claim that different sets of standards are "based on nothing but local, contingent, and varying causes of credibility" (3), and NONNEUTRALITY, the claim that the sets are "impossible to rank except on the basis of a specific [set]" (3). All three relativistic pretensions, Kusch says, are present in SSK (50f.). In response to criticism, Bloor especially often stepped back to a rather trivial form of methodological relativism instead of LOCALITY and NONNEUTRALITY and attacked those who attributed the latter ideas to him. For example, in obvious contrast to Kusch's NONNEUTRALITY, Bloor denounces Harvey Siegel's criticism by maintaining that Siegel "falsely attribute[s] to relativists the claim 'that there is no neutral way of choosing between ... alternative sets of standards'. Of course, this isn't the relativists' claim" (Bloor 2007, 257). In Kusch (2016), the contrast between NONNEUTRALITY and the quoted passage from Bloor is even more obvious: "Non-Neutrality: There is no neutral way of evaluating different SPs" (107). Since many critics of SSK have no major problems with its methodological relativism (cf. Siegel 2011, 47, Seidel 2014, 12) the reverse switcheroos performed by (some) SSK-proponents are debilitating. With Kusch's clarification perhaps we can finally stop the constant back and 
forth between radical, uncharitable interpretations of the Strong Program and the annoying 'We were always just claiming....'-trivialisations of the Strong Programers' relativism and make some progress in the debate. Perhaps the debate around SSK can finally revolve around the arguments for and against LOCALITY and NONNEUTRALITY.

Acknowledgements I would like to thank Julia Göhner for valuable comments on this review.

Funding Open Access funding enabled and organized by Projekt DEAL.

Open Access This article is licensed under a Creative Commons Attribution 4.0 International License, which permits use, sharing, adaptation, distribution and reproduction in any medium or format, as long as you give appropriate credit to the original author(s) and the source, provide a link to the Creative Commons licence, and indicate if changes were made. The images or other third party material in this article are included in the article's Creative Commons licence, unless indicated otherwise in a credit line to the material. If material is not included in the article's Creative Commons licence and your intended use is not permitted by statutory regulation or exceeds the permitted use, you will need to obtain permission directly from the copyright holder. To view a copy of this licence, visit http://creativecommons.org/licen ses/by/4.0/.

\section{References}

Bloor, D. 1991. Knowledge and Social Imagery, 2nd ed. Chicago/London: The University of Chicago Press.

Bloor, D. 2004. Sociology of Scientific Knowledge. In Handbook of Epistemology, ed. I. Niiniluoto, et al., 919-962. Dordrecht: Kluwer.

Bloor, D. 2007. 'Epistemic Grace. Antirelativism as Theology in Disguise', in: Common Knowledge 13 (2-3): 250-280.

Bloor, D. 2008. Relativism at 30,000 Feet. In Knowledge as social order: rethinking the sociology of barry barnes, ed. M. Mazzotti, 13-33. Aldershot: Ashgate.

Kukla, A. 2000. Social constructivism and the philosophy of science. London/New York: Routledge.

Kusch, M. 2016. Relativism in Feyerabend's later writings. Studies in History and Philosophy of Science A 57: 106-113.

Seidel, M. 2014. Epistemic relativism. A Constructive Critique. Basingstoke: Palgrave Macmillan.

Siegel, H. 2011. Relativism, incoherence, and the strong programme. In The problem of relativism in the sociology of (Scientific) knowledge, ed. R. Schantz and M. Seidel, 41-64. Frankfurt (Main): Ontos.

Publisher's Note Springer Nature remains neutral with regard to jurisdictional claims in published maps and institutional affiliations. 